\title{
How hard can it be? A study of word recognition of word forms with reduced segments
}

\author{
NICOLAI PHARAO, MIA RIDDER MALMSTEDT \& \\ SELINA VENG
}

Segmental reduction is highly frequent in conversational speech, which means that listeners are constantly exposed to words deviating from their distinctive, canonical pronunciation. The present study investigates whether there is a difference in how quickly and accurately listeners recognize reduced word forms compared to distinct word forms by means of an auditory lexical decision task. Participants were presented with reduced and unreduced words in isolation containing intervocalic $\mathrm{lg} /$ and with different degrees of lexical frequency as experimental stimuli. The results of the study demonstrate that reduction has a negative effect on word recognition, increasing response times as well as error rates, and that words of a higher frequency are more accurately identified than words of a lower frequency. Taken together the results show that there is a small but statistically significant benefit for listeners when processing distinct word forms compared to word forms containing a reduced segment. This supports a role for abstraction in representations in the mental lexicon. 